\title{
A Self-Powered Amperometric Lactate Biosensor Based on Lactate Oxidase Immobilized in Dimethylferrocene-Modified LPEI
}

\author{
David P. Hickey ${ }^{[a]}$, Russell C. Reid ${ }^{[b]}$, Ross D. Milton ${ }^{[a]}$, Shelley D. Minteer ${ }^{[a] *}$ \\ ${ }^{[a]}$ Department of Chemistry, University of Utah \\ ${ }^{[b]}$ Department of Mechanical Engineering, University of Utah \\ 315 South 1400 East, Salt Lake City, Utah 84112, United States \\ E-mail: minteer@chem.utah.edu
}

\begin{abstract}
Lactate is an important biomarker due to its excessive production by the body during anerobic metabolism. Existing methods for electrochemical lactate detection require the use of an external power source to supply a positive potential to the working electrode of a given device. Herein we describe a self-powered amperometric lactate biosensor that utilizes a dimethylferrocene-modified linear poly(ethylenimine) (FcMe2-LPEI) hydrogel to simultaneously immobilize and mediate electron transfer from lactate oxidase (LOx) at the anode and a previously described enzymatic cathode. Operating as a half-cell, the FcMe2-LPEI electrode material generates a $j_{\max }$ of $1.51 \pm 0.13 \mathrm{~mA} \mathrm{~cm}{ }^{-2}$ with a $K_{M}$ of $1.6 \pm 0.1$ and a sensitivity of $400 \pm 20 \mu \mathrm{A}$ $\mathrm{cm}^{-2} \mathrm{mM}^{-1}$ while operating with an applied potential of $0.3 \mathrm{~V}$ vs. SCE. When coupled with an enzymatic biocathode, the self-powered biosensor has a detection range between $0 \mathrm{mM}$ and $5 \mathrm{mM}$ lactate with a sensitivity of $45 \pm 6 \mu \mathrm{A} \mathrm{cm}^{-2} \mathrm{mM}^{-1}$. Additionally, the FcMe2-LPEI/LOx-based selfpowered sensor is capable of generating a power density of $122 \pm 5 \mu \mathrm{W} \mathrm{cm}{ }^{-2}$ with a current density
\end{abstract}


of $657 \pm 17 \mu \mathrm{A} \mathrm{cm}{ }^{-2}$ and an open circuit potential of $0.57 \pm 0.01 \mathrm{~V}$, which is sufficient to act as a supplemental power source for additional small electronic devices.

\section{Introduction}

Advancements in the expanding field of modern sports medicine have led to a growing interest in the development of methods to detect lactate in a continuous and convenient manner.(Nikolaus and Strehlitz 2008) Additionally, studies in the wider medical community have linked lactate concentration to various biological processes and medical conditions including tumor cell metastases and head trauma.(Cureton et al. 2010; Hirschhaeuser et al. 2011; Rassaei et al. 2014) Lactate is produced when endogenous glycogen in the muscle tissue is broken down through the glycolytic pathway to pyruvate which is subsequently reduced by lactate dehydrogenase.(Robergs et al. 2004) Throughout this process, the rate of lactate production far exceeds the rate of consumption and thus there is a buildup of lactate concentration that is proportional to the extent of physical exertion.(Falk et al. 1991; Green et al. 2004) Lactate is subsequently circulated throughout the body via the monocarboxylate transporter and can be detected in sweat, tears, urine, saliva, and serum (at typical concentrations of $20 \mathrm{mM}, 3 \mathrm{mM}, 0.1$ mM, 0.5 mM, and 1 mM, respectively).(Goodwin et al. 2007; Johnson and Edwards 1937; Meyer et al. 2007; Robergs et al. 2004; van Haeringen and Glasius 1977) The relative abundance of lactate in a broad range of accessible biological solutions and its physiological significance as a biomarker for both physical exercise and stress make lactate an important target in the field of biosensors. 
Many of the existing methods for the electrochemical detection of lactate utilize a first generation biosensor approach in which an enzyme, such as lactate oxidase (LOx), catalyzes the oxidation of lactate to produce $\mathrm{H}_{2} \mathrm{O}_{2}$ as a byproduct that is then detected amperometrically at a platinum electrode.(Faridnia et al. 1993; Goran et al. 2011; Lamas-Ardisana et al. 2014; Lei et al. 2012; Malon et al. 2014; Mascini et al. 1987) A similar approach uses the enzyme lactate dehydrogenase (LDH) and detects nicotinamide adenine dinucleotide hydrate (NADH), but this approach requires the addition of the oxidized form of $\mathrm{NADH}$, called $\mathrm{NAD}^{+}$, because it does not occur in sufficiently high concentrations in biological fluids.(Azzouzi et al. 2015; Nesakumar et al. 2014) Both of these methods require the use of a standard three electrode cell with a reference, counter, and working electrode, for which a relatively large potential must be applied to facilitate the detection of peroxide or NADH. The large applied potential also results in artificially inflated current caused by the unwanted oxidation of biological contaminants. A possible solution to this problem is to utilize high current density redox mediators to facilitate electron transfer from the flavin adenine dinucleotide (FAD) active site of LOx to the electrode surface at a lower potential than that required for $\mathrm{H}_{2} \mathrm{O}_{2}$ oxidation.(Casero et al. 2014; Gamero et al. 2012; Qin et al. 2012) Additionally, such materials can be coupled with a biocathode to provide the electrochemical driving force required for lactate detection; such a device can then function as a self-powered lactate sensor to eliminate the need for an external power source.

Self-powered biosensors allow for the use of a simplified two electrode cell and do not require an externally applied potential to operate. Additionally, such devices are powered by biological fluids and are therefore ideal as implantable sensors. The concept for a self-powered biosensor was first described by Katz et al. as a potentiometric device for the detection of both glucose and lactate.(Katz et al. 2001) Subsequent research efforts on self-powered sensors have 
primarily focused on the amperometric detection of glucose, however very little research has been performed on self-powered lactate biosensors due to the low current densities generated by peroxide oxidation.(Meredith and Minteer 2011; Wang 2012; Zhou and Dong 2011; Zhou and Wang 2012) Some recent work has utilized tetrathiafulvalene (TTF) and Prussian Blue as redox mediators to minimize the applied potential necessary for adequate detection.(Jia et al. 2013; Pribil et al. 2014) However, the currents generated by such methods are still not enough to power their own operation, and thus further research into high-current density lactate sensors is needed.

Ferrocene-modified polymers such as linear poly(ethylenimine) (LPEI) have been previously used to simultaneously immobilize and mediate electron transfer of FAD-dependent oxidoreductase enzymes.(Heller 1990; Meredith et al. 2011a) Rapid rates of self-exchange for ferrocene compounds allow for efficient electron shuttling between an enzymatic active site and the electrode surface. Additionally, the use of polymethylated ferrocene moieties has been shown to allow for a lower oxidative overpotential relative to unmethylated ferrocene which minimizes inaccuracies caused by interferents such as ascorbic acid.(Meredith et al. 2013) In the work presented here, we report the use of a dimethylferrocene-modified LPEI (FcMe2-LPEI) to immobilize LOx onto a carbon electrode as a lactate sensor. The biosensor was characterized by constant potential amperometry to determine its sensitivity and limit of detection as well as for the determination of optimal $\mathrm{pH}$ and temperature. Additionally, the current density generated was substantial enough to couple with a previously reported bilirubin oxidase (BOD) based biocathode to make a biofuel cell capable of providing the electrochemical driving force required for lactate detection without an external power source.(Meredith et al. 2011b) A scheme of this self-powered biosensor is shown in Figure 1. 


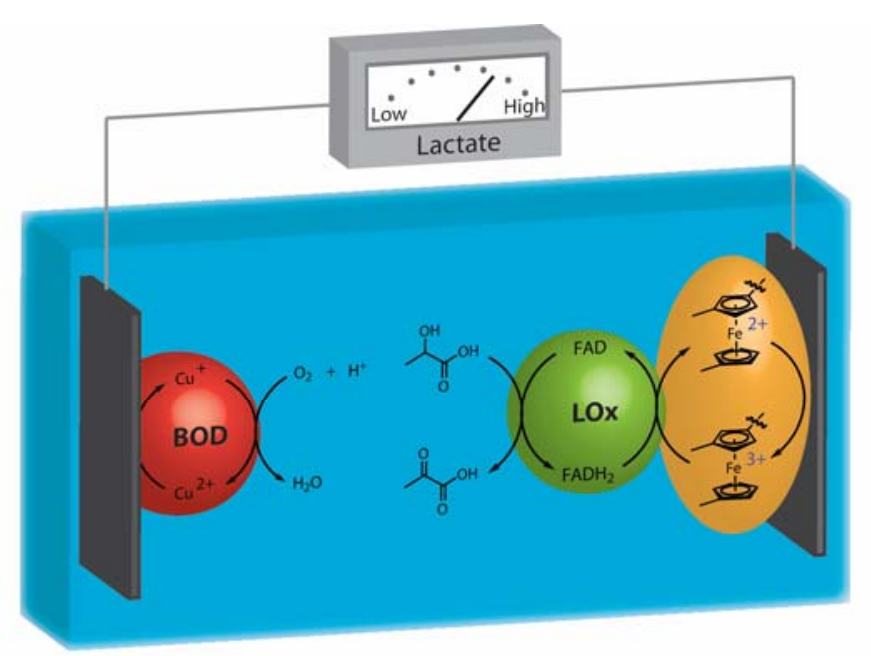

Figure 1 - Schematic of a self-powered lactate sensor consisting of a bilirubin oxidase-based cathode and a ferrocene-mediated lactate oxidase-based anode.

\section{Materials and Methods}

\subsection{Chemicals}

All chemicals were of reagent grade and were, unless otherwise specified, used without further modification. Sodium lactate, lactic acid, phosphoric acid, boric acid, acetic acid, sodium hydroxide, and lactate oxidase (LOx) from Pediococcus sp. were obtained from Sigma Aldrich. The LOx (Sigma L0638, activity 200 U/ml) was dissolved in a phosphate buffer at pH 6.5, divided into aliquots, and kept at $-20{ }^{\circ} \mathrm{C}$ until immediately before being used. Ethylene glycol diglycidyl ether (EGDGE) was obtained from Polysciences, Inc. Billirubin oxidase (BOx) was a gift from Amano Enzyme, Inc. Tetrabutylammonium bromide (TBAB)-modified Nafion was prepared as described previously.(Treu and Minteer 2008)

\subsection{Electrode preparation}


Test samples were prepared using $3 \mathrm{~mm}$ diameter $\left(0.0707 \mathrm{~cm}^{2}\right)$ glassy carbon electrodes from CH Instruments, Inc. and $0.25 \mathrm{~cm}^{2}$ buckypaper electrodes from National Composites Center (C-grade MWNT, 27 gsm). Glassy carbon electrodes were used for basic lactate sensor characterization and buckypaper was used to demonstrate sensor performance on a material that could be integrated into a wearable device such as a lactate patch sensor or a contact lens biofuel cell.(Jia et al. 2013; Reid et al. 2015) Glassy carbon electrodes were thoroughly polished before use and buckypaper electrodes were cleaned by oxygen plasma for 5 minutes using a PDC-32G plasma cleaner from Harrick. A previously developed redox polymer was used to mediate electron transfer between LOx and the electrodes. The redox polymer used here was a dimethylferrocenemodified linear polyethyleneimine (FcMe2-LPEI) and was prepared as previously reported.(Meredith et al. 2011a) Solutions of $10 \mathrm{mg} \mathrm{mL}^{-1}$ FcMe2-LPEI in deionized (DI) water, $200 \mathrm{U} \mathrm{mL}^{-1}$ LOx in phosphate buffer, and 2-6\% v / v EGDGE in DI water were prepared immediately prior to use. These three solutions were then combined in a volumetric ratio of 56 /24/3 of FcMe2-LPEI/LOx/EGDGE and thoroughly mixed. Then, $3 \mu \mathrm{L}$ and $25 \mu \mathrm{L}$ was pipetted onto each glassy carbon and bucky-paper electrode, respectively, and allowed to cure overnight.

Biocathodes for the self-powered lactate sensor consisted of $3.18 \mathrm{~mm}$-thick carbon felt from Alfa Aesar coated with a solution of anthracene-modified multi-walled carbon nanotubes (An-CNTs), BOD, $50 \mathrm{mM}$ phosphate buffer at pH 6.5, and TBAB-Nafion. The An-CNTs were produced as previously reported.(Giroud and Minteer 2013; Meredith et al. 2011b) To prepare 3 cathodes with a geometric area of $1 \mathrm{~cm}^{2}$ each, $7.5 \mathrm{mg}$ of BOD was dissolved in $750 \mu \mathrm{l}$ of phosphate buffer. To that solution, $37.5 \mathrm{mg}$ of An-CNTs was added and the mixture was vortexed for 1 minute, sonicated for 30 seconds and vortexed and sonicated two more times for the same time durations.(Milton et al. 2015) $250 \mu$ of TBAB-Nafion was added and the solution was vortexed 
and sonicated one more time. Finally, $300 \mu$ l of solution was coated onto each cathode and allowed to dry for 3 hours.

\subsection{Electrochemical methods}

All electrochemical experiments were performed in triplicate with triplicate prepared electrodes. All uncertainties correspond to the standard deviation of those triplicate measurements. All electrochemical experiments were performed with moderate stirring and using either a CHI600 series potentiostat from $\mathrm{CH}$ Instruments or a DY2300 potentiostat from Digi-Ivy. A 50 mM phosphate buffer adjusted to $\mathrm{pH} 6.5$ with $4 \mathrm{M} \mathrm{NaOH}$ was used for all experiments except for $\mathrm{pH}$ dependence where a Britton-Robinson buffer (40 mM borate, $40 \mathrm{mM}$ phosphate, $40 \mathrm{mM}$ acetate) was used for its buffering range from $\mathrm{pH}$ 2-12. A platinum mesh counter electrode and a saturated calomel electrode (SCE) reference were used for all experiments except the self-powered sensor tests. All voltammetric experiments were performed with a scan rate of $2 \mathrm{mV} \mathrm{s}^{-1}$ and amperometric experiments were all accomplished using an applied voltage of approximately $50 \mathrm{mV}$ above $E_{\text {ipa }}$ (0.3 V vs. SCE). The temperature dependence data was collected while using a Cole Parmer Polystat recirculator to control the solution temperature. All current densities were calculated using the geometric surface area of the electrode face (i.e. $0.707 \mathrm{~cm}^{2}$ for glassy carbon electrodes, and $0.25 \mathrm{~cm}^{2}$ for all Bucky paper electrodes).

Power curves for the self-powered lactate sensors were generated voltammetrically by performing linear sweep voltammetry on the cell while using the FcMe2-LPEI/LOx anode as the reference and counter electrode, and the An-CNT/Laccase cathode as the working electrode. In order to mimic a constant-resistance device, the voltammetrically-determined power curves were used to calculate the effective resistance at each corresponding current density. The lactate calibration curve from the self-powered sensor was then generated by taking the voltammetrically- 
derived current response at the same calculated resistance $(2.5 \mathrm{k} \Omega$ ) using different lactate concentrations.

\section{Results and Discussion}

\subsection{Electrochemical Characterization of Lactate Sensor}

Lactate biosensors were prepared by cross-linking FcMe2-LPEI onto a carbon electrode with ethylene glycol diglycidyl ether (EGDGE) in the presence of LOx. The FcMe2-LPEI redox polymer used here was previously shown to effectively mediate electron transfer between the FAD active site of an enzyme, glucose oxidase (GOx), and the surface of an electrode in the context of a glucose biosensor/biofuel cell.(Meredith et al. 2013) The cross-linked FcMe2-LPEI film forms a hydrogel that swells to several times its original volume which facilitates sufficient diffusion of substrate through the polymer matrix. Additionally, the swelling capability of the polymer film allows for high segmental mobility of the redox-active side chains which in turn facilitates a high rate of electron transfer via electron self-exchange between ferrocene moieties.(Hickey et al. 2014)

A comparative cyclic voltammogram is shown in Figure 2A of the FcMe2-LPEI/LOx film on a glassy carbon electrode in the absence and presence of lactate. A characteristic reversible redox couple for dimethylferrocene is present in the cyclic voltammetry with an oxidation potential of $0.240 \mathrm{~V}$ vs. SCE and results in a mediated catalytic current density $\left(j_{\max }\right)$ of $386 \mu \mathrm{A} \mathrm{cm}{ }^{-2}$. The low oxidation potential of the ferrocene moiety relative to that of peroxide allows for a significantly lower applied potential for operation of the biosensor. A calibration curve for lactate detection by FcMe2-LPEI films, shown in Figure 2B, indicates a linear response range from $0 \mathrm{mM}$ lactate up to $5 \mathrm{mM}$ lactate with a reproducible detection limit of $3 \mu \mathrm{M}$ lactate. Additionally, the calibration curve was fitted to traditional Michaelis-Menten kinetic parameters which resulted in 
a calculated $j_{\max }$ of $460 \pm 14 \mu \mathrm{A} \mathrm{cm}{ }^{-2}$ and a Michaelis-Menten constant $\left(K_{M}\right)$ of $2.3 \pm 0.3 \mathrm{mM}$.

While this sensor would not be suitable under the current conditions for the detection of lactate in undiluted physiological sweat samples where lactate concentrations can be higher than $20 \mathrm{mM}$, the combination of a large value of $j_{\max }$ and a small $K_{M}$ allows for a high sensitivity within physiological concentrations of lactate found in tears, urine, and serum under typical conditions. Under intense physical exertion, however, lactate concentration in these fluids can approach 10 $\mathrm{mM}$, which is still within the detection range for this sensor but at a lower sensitivity.

A.

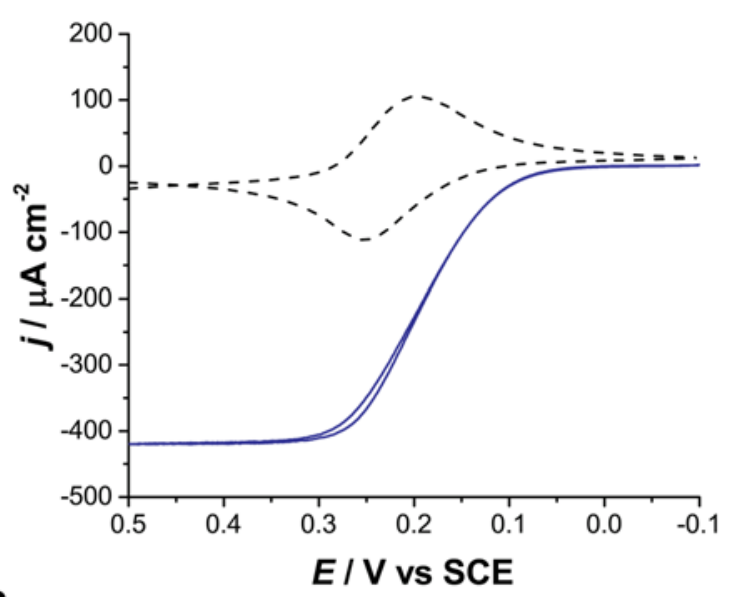

B.

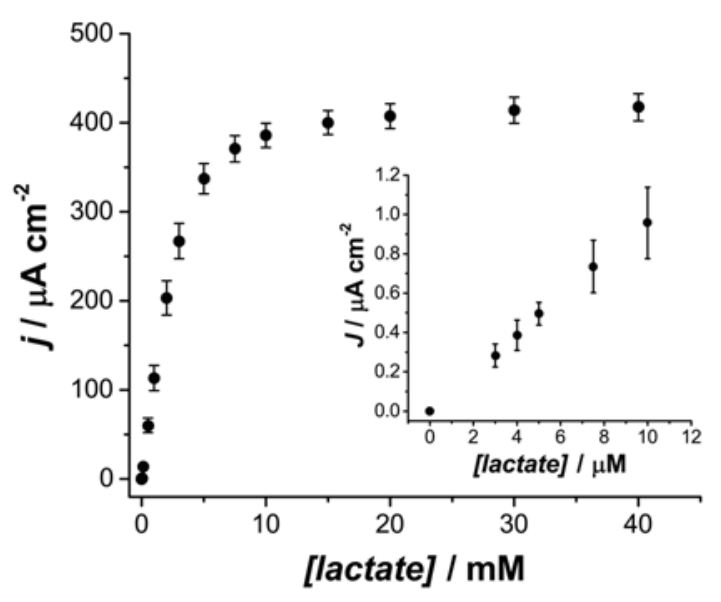

Figure 2. (A) Catalytic cyclic voltammogram of $\mathrm{FcMe}_{2}-\mathrm{LPEI} / \mathrm{LOx}$ film on a glassy carbon electrode in the absence (dashed) and presence (solid) of $40 \mathrm{mM}$ lactate; performed at $2 \mathrm{mV} \mathrm{sec}^{-1}$. (B) Calibration curve of FcMe-LPEI films with the lower concentration range inset (where error bars represent one standard deviation from the mean, $\mathrm{n}=3$ ). Experiments were performed using a $3 \mathrm{~mm}$ glassy carbon electrode and $50 \mathrm{mM}$ phosphate buffer at $\mathrm{pH} 6.5$ and $25^{\circ} \mathrm{C}$. 
With a working sensor in hand, we sought to determine the effect of both temperature and $\mathrm{pH}$ on the activity of the FcMe2-LPEI/LOx films to ensure reasonable activity under the desired operating conditions. Plots of $j_{\max }$ as a function of temperature and $\mathrm{pH}$ for FcMe2-LPEI/LOx films are shown in Figure 3. These $\mathrm{pH}$ and temperature profiles indicate that FcMe2-LPEI/LOX films reach maximum catalytic activity at $\mathrm{pH} 9$ and between 37 and $40^{\circ} \mathrm{C}$. These results are consistent with the reported literature on the activity of free LOx in solution, which indicates that the FcMe2LPEI polymer used to immobilize the enzyme does not significantly interfere with its characteristic activity.(Lowinsohn and Bertotti 2008) Additionally, it should be noted that under physiological conditions ( $\mathrm{pH} 7.4$ and $37^{\circ} \mathrm{C}$ ), the electrode film is within $85 \%$ of its maximum activity with respect to both temperature and $\mathrm{pH}$. The ability to maintain activity under these conditions is crucial when considering the possibility of using FcMe2-LPEI/LOx as an implantable sensor. 
A.

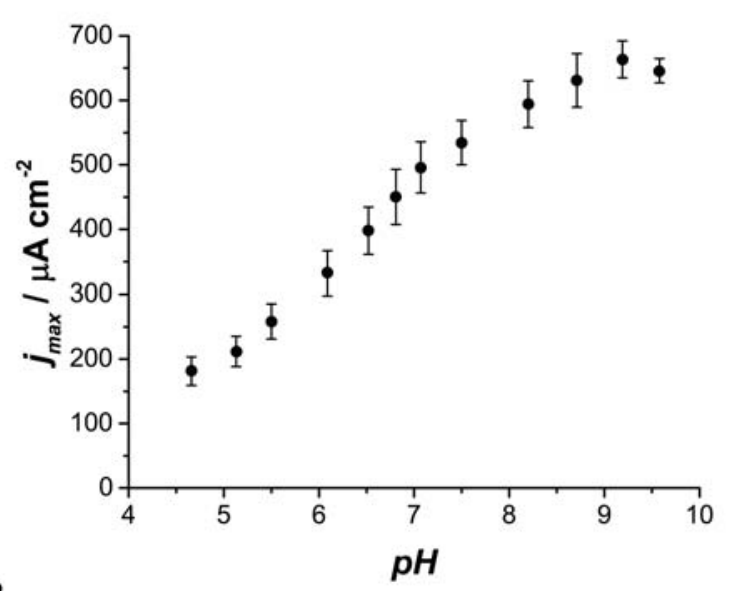

B.

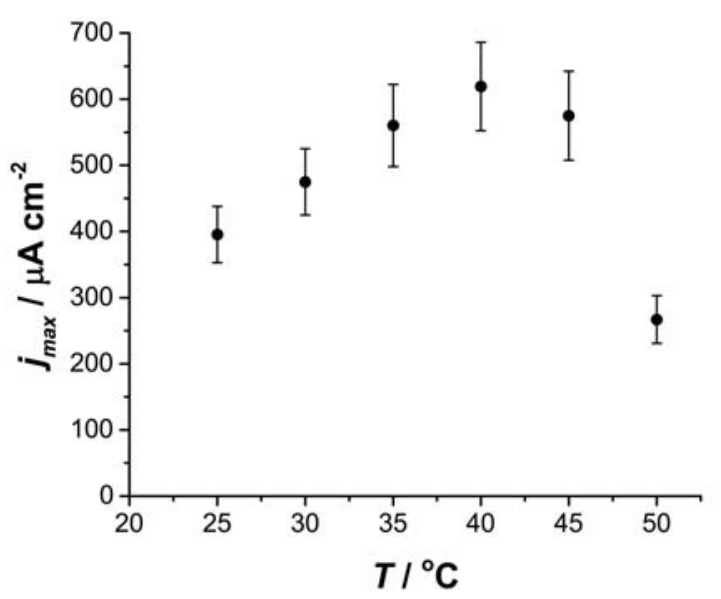

Figure 3. Temperature (A) and $\mathrm{pH}(\mathrm{B})$ profiles of $\mathrm{FcMe}_{2}-\mathrm{LPEI} / \mathrm{LOx}$ films on $3 \mathrm{~mm}$ glassy carbon electrodes. Experiments were performed using either $50 \mathrm{mM}$ phosphate buffer at $\mathrm{pH} 6.5$ (A) or $40 \mathrm{mM}$ Robinson buffer with variable $\mathrm{pH}(\mathrm{B})$, and $40 \mathrm{mM}$ lactate at $25^{\circ} \mathrm{C}$. Error bars represent one standard deviation from the mean, $\mathrm{n}=3$.

\subsection{Scaled Sensor on Bucky Paper}

Fundamental characterization of the lactate sensor was performed on a glassy carbon electrode to minimize the possibility of anomalous effects seen with some high surface electrode materials. However, once the sensor was sufficiently characterized, we turned to the use of a high surface area electrode in order to translate the FcMe2-LPEI/LOx film into a practical material for lactate detection. Buckypaper is a carbon paper comprised of multi-walled carbon nanotubes (MWCNT) pressed together to form a sheet that is bendable and yet maintains the excellent 
porosity, surface area, and resistivity of other carbon paper electrodes. In addition, forming MWCNTs into a sheet does not remove their ability to be chemically functionalized to detect a wide range of analytes. This makes buckypaper an attractive electrode material for implantable and wearable sensors requiring flexibility for adhering to non-planar surfaces or for repeated bending while in use.

Amperometric response profiles to lactate were generated for FcMe2-LPEI/LOx films on buckypaper to serve as a comparison of the kinetic parameters between the two types of electrode materials. The resulting calibration curve, shown in Figure 4, was fitted as above to give a $j_{\max }$ of $1650 \pm 190 \mu \mathrm{A} \mathrm{cm}{ }^{-2}$ and a $K_{M}$ of $1.6 \pm 0.1 \mathrm{mM}$ with a detection limit of $1 \mu \mathrm{M}$ lactate. The values of these kinetic parameters indicate that the use of a high-surface area buckypaper electrode has the effect of increasing the maximum current and sensitivity without significantly affecting the apparent binding constant of the enzyme. The ability to generate such high current densities is important as it allows for the high sensitivity needed to differentiate various lactate concentrations in a practical self-powered biosensor. Other considerations for practical biosensor development are the selectivity and shelf-life of the device. 
A.

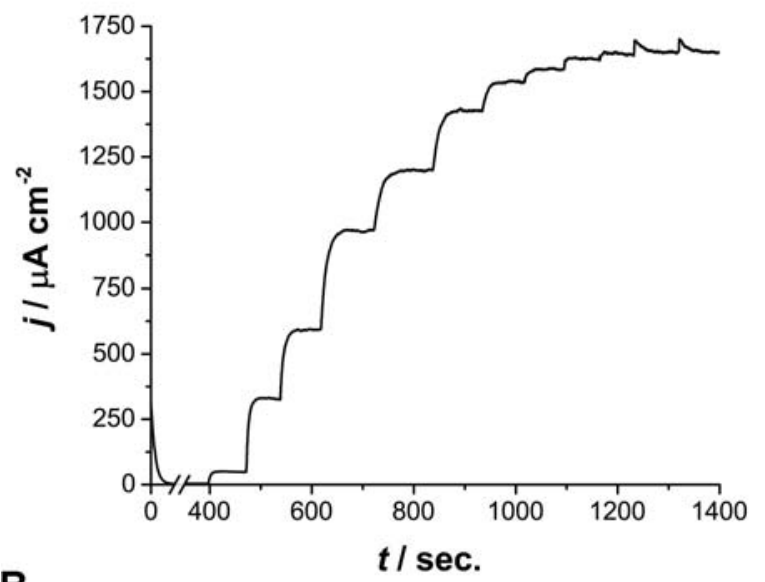

B.

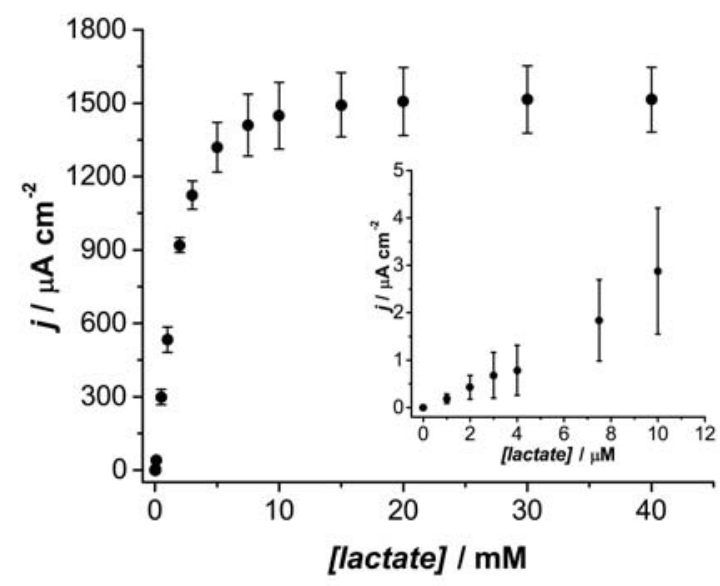

Figure 4. Amperometric response (A) and the resulting calibration curve (B) of FcMe2-LPEI/LOx films on buckypaper electrodes to various concentrations of lactate. Experiments were performed using $50 \mathrm{mM}$ phosphate buffer at $\mathrm{pH} 6.5$ and $25^{\circ} \mathrm{C}$. Error bars represent one standard deviation from the mean, $\mathrm{n}=3$.

Constant potential amperometry was used to determine the response of FcMe2-LPEI/LOx films to a commonly tested biological interferent, ascorbate.(Nikolaus and Strehlitz 2008) The resulting calibration curve for ascorbate is shown in Figure 5A. An amperometric response ranging from $124 \pm 6 \mu \mathrm{A} \mathrm{cm} \mathrm{cm}^{-2}$ to $185 \pm 14 \mu \mathrm{A} \mathrm{cm} \mathrm{cm}^{-2}$ under physiological concentrations of ascorbate. The absolute magnitude of the sensor's response to ascorbate is less than $50 \%$ of the corresponding response to a change of $1 \mathrm{mM}$ lactate. In addition, the range for amperometric 
responses of FcMe2-LPEI/LOx films to ascorbate does not change significantly with respect to the lactate sensitivity of the sensor.

The stability of FcMe2-LPEI/LOx films on buckypaper was determined by preparing films and storing them at $4{ }^{\circ} \mathrm{C}$ for various lengths of time before testing their amperometric response to lactate. The storage stability of FcMe2-LPEI/LOx films is shown in Figure 5B, and indicates that such films on buckypaper do not significantly lose any activity even after storage for up to 21 days. It should be noted that films may be stable for significantly longer than this, but further long-term storage stability tests are needed.

A.

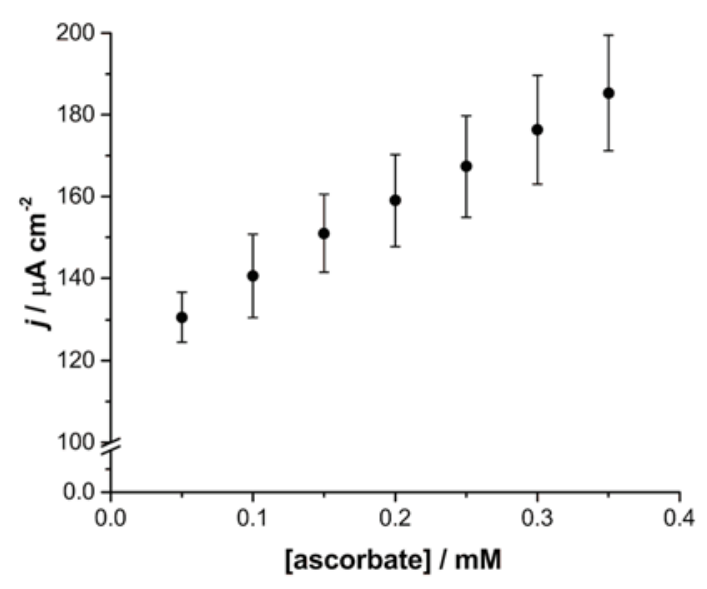

B.

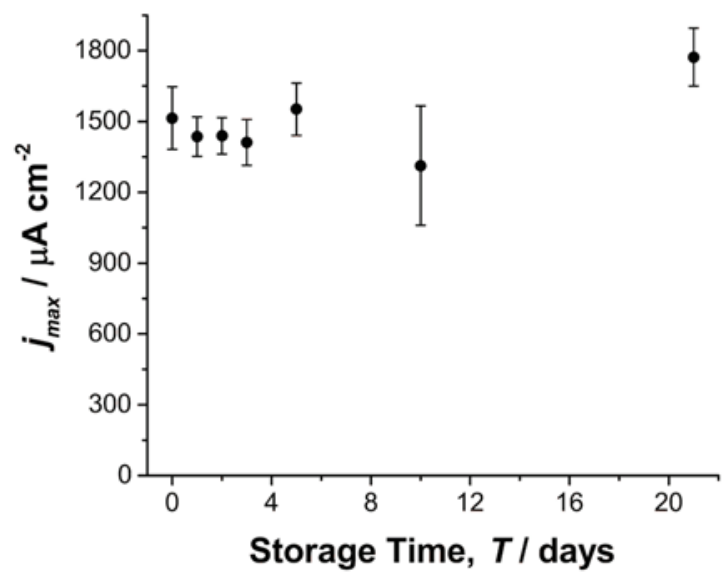


Figure 5. Amperometric response of $\mathrm{FcMe}_{2}-\mathrm{LPEI} / \mathrm{LOx}$ films on buckypaper to ascorbate (A) and storage stability of $\mathrm{FcMe}_{2}$-LPEI/LOx films on buckypaper electrodes (B). For storage stability, films were stored at $4{ }^{\circ} \mathrm{C}$ and activity to both ascorbate and lactate was determined using $50 \mathrm{mM}$ phosphate buffer at $\mathrm{pH} 6.5$ and $25^{\circ} \mathrm{C}$. Error bars represent one standard deviation from the mean, $\mathrm{n}=3$.

\subsection{Self-Powered Lactate Sensor}

The improved sensitivity of the FcMe2-LPEI/LOx films on buckypaper coupled with the high current densities that were produced were sufficient to utilize the newly developed lactate sensor in a self-powered configuration. A self-powered lactate sensor was constructed by coupling the FcMe2-LPEI/LOx film with a previously described enzymatic biocathode that uses anthracenemodified carbon nanotubes (An-CNTs) as a means of immobilizing the enzyme, bilirubin oxidase (BOD), for the reduction of molecular oxygen. In this configuration, the An-CNT/BOD cathode spontaneously reduces $\mathrm{O}_{2}$ to water under ambient aqueous conditions which in turn generates the positive potential required for the lactate-sensing anode.(Meredith et al. 2011b) The current is measured when the electrodes are connected over a fixed resistance to determine the concentration of lactate.

Power curves of the FcMe2-LPEI/LOx|An-CNT/BOD self-powered sensor at various concentrations of lactate are shown in Figure 6 along with the corresponding calibration curve. A considerable transport limitation area can be seen in the low resistance region of the power curves at every lactate concentration studied which indicates that there is slow diffusion of product away from the electrode at either the anode or the cathode. However, a linear response of current density to lactate concentration is observed in a concentration range that is consistent with the anodic halfcell. The open circuit potential for all non-zero concentrations of lactate was in the range from $0.567 \mathrm{~V}$ to $0.580 \mathrm{~V}$ (with an average of $0.57 \pm 0.01 \mathrm{~V}$ ) while the current density of the self-powered sensor reached as high as $650 \mu \mathrm{A} \mathrm{cm}^{-2}$ in the presence of $5 \mathrm{mM}$ lactate. While the linear range of 
the sensor limits the analytical solutions that can be tested, the high current and power density generated under physiological concentrations of lactate could allow for the use of this material either as an implantable or wearable biofuel cell. It should also be noted that the limiting component to this device is certainly the cathode material. The relatively low current density generated at the cathode provides a limit to the sensitivity that can be achieved, and thus any improvements on this device should be aimed at the development of more effective cathode materials.

A.

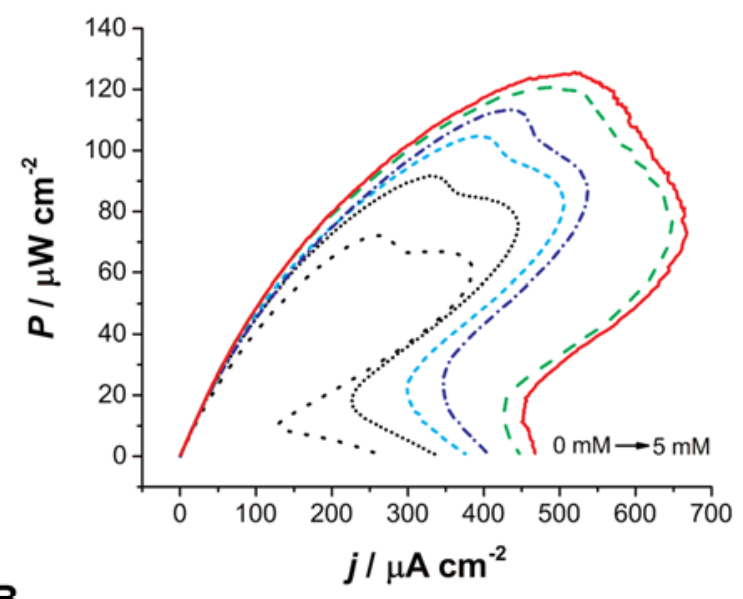

B.

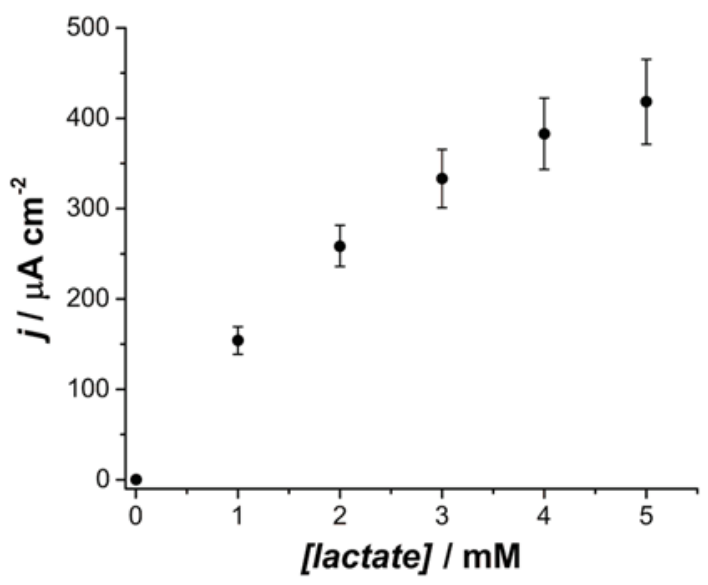

Figure 6. Power curves (A) and corresponding calibration curve (B) for FcMe 2 -LPEI/LOx|An-CNT/BOD selfpowered lactate sensors. Experiments were performed using $50 \mathrm{mM}$ phosphate buffer at $\mathrm{pH} 6.5$ and $25^{\circ} \mathrm{C}$. Error bars represent one standard deviation from the mean, $n=3$. 


\section{Conclusions}

Self-powered biosensors allow for the electrochemical detection of a biological analyte without the need of an external power source to supply a potential to the working electrode. We have presented a ferrocene-mediated lactate sensor capable of generating sufficient current density to operate as the anode of a self-powered lactate sensor. The amperometric sensor was prepared by immobilizing LOx onto an electrode surface with a cross-linked film of FcMe2-LPEI. The FcMe2-LPEI/LOx biosensor material exhibits maximum catalytic activity under near physiological $\mathrm{pH}$ and temperature and can be stored for up to 21 days without significant loss of activity. We coupled this material with an enzymatic biocathode to construct a self-powered lactate biosensor with a linear amperometric response range between 0 and $5 \mathrm{mM}$ lactate and an open circuit potential of $0.57 \pm 0.01 \mathrm{~V}$. Additionally, the self-powered sensor was capable of generating a maximum power density of $122 \pm 5 \mu \mathrm{W} \mathrm{cm}{ }^{-2}$ and a maximum current density of $657 \pm 17 \mu \mathrm{A}$ $\mathrm{cm}^{-2}$. A possible approach moving forward is to couple this self-powered sensor to a triboelectric or piezoelectric generator as a supplemental power supply to enhance the operational stability of an applied device.(Hansen et al. 2010; Ramadoss et al. 2015; Yang et al. 2013) Future studies must still be performed to determine the potential toxicity effects of long-term use of such devices, and ongoing research is aimed at utilizing these high-current density materials to engineer practical self-powered biosensors and biofuel cells into both wearable and implantable devices. 


\section{Acknowledgments}

The work presented here was funded by the National Science Foundation (Grant \#1158943).

\section{References}

Azzouzi, S., Rotariu, L., Benito, A.M., Maser, W.K., Ben Ali, M., Bala, C., 2015. A novel amperometric biosensor based on gold nanoparticles anchored on reduced graphene oxide for sensitive detection of l-lactate tumor biomarker. Biosens. Bioelectron. 69(0), 280-286.

Casero, E., Alonso, C., Petit-Domínguez, M., Vázquez, L., Parra-Alfambra, A., Merino, P., Álvarez-García, S., de Andrés, A., Suárez, E., Pariente, F., Lorenzo, E., 2014. Lactate biosensor based on a bionanocomposite composed of titanium oxide nanoparticles, photocatalytically reduced graphene, and lactate oxidase. Microchim Acta 181(1-2), 79-87.

Cureton, E.L., Kwan, R.O., Dozier, K.C., Sadjadi, J., Pal, J.D., Victorino, G.P., 2010. A Different View of Lactate in Trauma Patients: Protecting the Injured Brain. Journal of Surgical Research 159(1), 468-473.

Falk, B., Bar-Or, O., MacDougall, J.D., McGillis, L., Calvert, R., Meyer, F., 1991. Sweat lactate in exercising children and adolescents of varying physical maturity.

Faridnia, M.H., Palleschi, G., Lubrano, G.J., Guilbault, G.G., 1993. Amperometric biosensor for determination of lactate in sweat. Anal. Chim. Acta 278(1), 35-40.

Gamero, M., Sosna, M., Pariente, F., Lorenzo, E., Bartlett, P.N., Alonso, C., 2012. Influence of macroporous gold support and its functionalization on lactate oxidase-based biosensors response. Talanta 94(0), 328-334.

Giroud, F., Minteer, S.D., 2013. Anthracene-modified pyrenes immobilized on carbon nanotubes for direct electroreduction of O2 by laccase. Electrochem. Commun. 34(0), 157-160.

Goodwin, M.L., Harris, J.E., Hernández, A., Gladden, L.B., 2007. Blood Lactate Measurements and Analysis during Exercise: A Guide for Clinicians. Journal of Diabetes Science and Technology 1(4), 558-569.

Goran, J.M., Lyon, J.L., Stevenson, K.J., 2011. Amperometric Detection of l-Lactate Using Nitrogen-Doped Carbon Nanotubes Modified with Lactate Oxidase. Anal. Chem. 83(21), 81238129.

Green, J.M., Pritchett, R.C., Tucker, D.C., Crews, T.R., McLester, J.R., 2004. Sweat lactate response during cycling at $30^{\circ} \mathrm{C}$ and $18^{\circ} \mathrm{C}$ WBGT. Journal of Sports Sciences 22(4), 321-327.

Hansen, B.J., Liu, Y., Yang, R., Wang, Z.L., 2010. Hybrid Nanogenerator for Concurrently Harvesting Biomechanical and Biochemical Energy. ACS Nano 4(7), 3647-3652.

Heller, A., 1990. Electrical wiring of redox enzymes. Accounts of Chemical Research 23(5), 128134. 
Hickey, D.P., Halmes, A.J., Schmidtke, D.W., Glatzhofer, D.T., 2014. Electrochemical Characterization of Glucose Bioanodes Based on Tetramethylferrocene-Modified Linear Poly(ethylenimine). Electrochim. Acta 149(0), 252-257.

Hirschhaeuser, F., Sattler, U.G.A., Mueller-Klieser, W., 2011. Lactate: A Metabolic Key Player in Cancer. Cancer Research 71(22), 6921-6925.

Jia, W., Bandodkar, A.J., Valdés-Ramírez, G., Windmiller, J.R., Yang, Z., Ramírez, J., Chan, G., Wang, J., 2013. Electrochemical Tattoo Biosensors for Real-Time Noninvasive Lactate Monitoring in Human Perspiration. Anal. Chem. 85(14), 6553-6560.

Johnson, R.E., Edwards, H.T., 1937. LACTATE AND PYRUVATE IN BLOOD AND URINE AFTER EXERCISE. J. Biol. Chem. 118(2), 427-432.

Katz, E., Bückmann, A.F., Willner, I., 2001. Self-Powered Enzyme-Based Biosensors. J. Am. Chem. Soc. 123(43), 10752-10753.

Lamas-Ardisana, P.J., Loaiza, O.A., Añorga, L., Jubete, E., Borghei, M., Ruiz, V., Ochoteco, E., Cabañero, G., Grande, H.J., 2014. Disposable amperometric biosensor based on lactate oxidase immobilised on platinum nanoparticle-decorated carbon nanofiber and poly(diallyldimethylammonium chloride) films. Biosens. Bioelectron. 56(0), 345-351.

Lei, Y., Luo, N., Yan, X., Zhao, Y., Zhang, G., Zhang, Y., 2012. A highly sensitive electrochemical biosensor based on zinc oxide nanotetrapods for l-lactic acid detection. Nanoscale 4(11), 34383443.

Lowinsohn, D., Bertotti, M., 2008. A biosensor based on immobilization of lactate oxidase in a PB-CTAB film for FIA determination of lactate in beer samples. Journal of the Brazilian Chemical Society 19, 637-642.

Malon, R.S.P., Chua, K.Y., Wicaksono, D.H.B., Corcoles, E.P., 2014. Cotton fabric-based electrochemical device for lactate measurement in saliva. Analyst 139(12), 3009-3016.

Mascini, M., Mazzei, F., Moscone, D., Calabrese, G., Benedetti, M.M., 1987. Lactate and pyruvate electrochemical biosensors for whole blood in extracorporeal experiments with an endocrine artificial pancreas. Clin. Chem. 33(4), 591-593.

Meredith, M.T., Hickey, D.P., Redemann, J.P., Schmidtke, D.W., Glatzhofer, D.T., 2013. Effects of Ferrocene Methylation on Ferrocene-Modified Linear Poly(ethylenimine) Bioanodes. Electrochim. Acta 92(0), 226-235.

Meredith, M.T., Kao, D.-Y., Hickey, D., Schmidtke, D.W., Glatzhofer, D.T., 2011a. High Current Density Ferrocene-Modified Linear Poly(ethylenimine) Bioanodes and Their Use in Biofuel Cells. J. Electrochem. Soc. 158(2), B166-B174.

Meredith, M.T., Minson, M., Hickey, D., Artyushkova, K., Glatzhofer, D.T., Minteer, S.D., $2011 b$. Anthracene-Modified Multi-Walled Carbon Nanotubes as Direct Electron Transfer Scaffolds for Enzymatic Oxygen Reduction. ACS Cat. 1(12), 1683-1690.

Meredith, M.T., Minteer, S.D., 2011. Inhibition and Activation of Glucose Oxidase Bioanodes for Use in a Self-Powered EDTA Sensor. Anal. Chem. 83(13), 5436-5441.

Meyer, F., Laitano, O., Bar-Or, O., McDougall, D., Heigenhauser, G.J.F., 2007. Effect of age and gender on sweat lactate and ammonia concentrations during exercise in the heat. Brazilian Journal of Medical and Biological Research 40, 135-143.

Milton, R.D., Hickey, D.P., Abdellaoui, S., Lim, K., Wu, F., Tan, B., Minteer, S.D., 2015. Rational design of quinones for high power density biofuel cells. Chemical Science.

Nesakumar, N., Thandavan, K., Sethuraman, S., Krishnan, U.M., Rayappan, J.B.B., 2014. An electrochemical biosensor with nanointerface for lactate detection based on lactate dehydrogenase immobilized on zinc oxide nanorods. J. Colloid Interface Sci. 414(0), 90-96. 
Nikolaus, N., Strehlitz, B., 2008. Amperometric lactate biosensors and their application in (sports) medicine, for life quality and wellbeing. Microchim Acta 160(1-2), 15-55.

Pribil, M.M., Laptev, G.U., Karyakina, E.E., Karyakin, A.A., 2014. Noninvasive Hypoxia Monitor Based on Gene-Free Engineering of Lactate Oxidase for Analysis of Undiluted Sweat. Anal. Chem. 86(11), 5215-5219.

Qin, C., Chen, C., Xie, Q., Wang, L., He, X., Huang, Y., Zhou, Y., Xie, F., Yang, D., Yao, S., 2012. Amperometric enzyme electrodes of glucose and lactate based on poly(diallyldimethylammonium)-alginate-metal ion-enzyme biocomposites. Anal. Chim. Acta 720(0), 49-56.

Ramadoss, A., Saravanakumar, B., Lee, S.W., Kim, Y.-S., Kim, S.J., Wang, Z.L., 2015. Piezoelectric-Driven Self-Charging Supercapacitor Power Cell. ACS Nano 9(4), 4337-4345.

Rassaei, L., Olthuis, W., Tsujimura, S., Sudhölter, E.R., van den Berg, A., 2014. Lactate biosensors: current status and outlook. Analytical and Bioanalytical Chemistry 406(1), 123-137.

Reid, R.C., Minteer, S.D., Gale, B.K., 2015. Contact lens biofuel cell tested in a synthetic tear solution. Biosens. Bioelectron. 68(0), 142-148.

Robergs, R.A., Ghiasvand, F., Parker, D., 2004. Biochemistry of exercise-induced metabolic acidosis.

Treu, B.L., Minteer, S.D., 2008. Isolation and purification of PQQ-dependent lactate dehydrogenase from Gluconobacter and use for direct electron transfer at carbon and gold electrodes. Bioelectrochemistry 74(1), 73-77.

van Haeringen, N.J., Glasius, E., 1977. Collection method dependant concentrations of some metabolites in human tear fluid, with special reference to glucose in hyperglycaemic conditions. Albrecht von Graefes Arch. Klin. Ophthalmol. 202(1), 1-7.

Wang, Z.L., 2012. Self-Powered Nanosensors and Nanosystems. Adv. Mater. 24(2), 280-285.

Yang, Y., Zhang, H., Chen, J., Lee, S., Hou, T.-C., Wang, Z.L., 2013. Simultaneously harvesting mechanical and chemical energies by a hybrid cell for self-powered biosensors and personal electronics. Energy \& Environmental Science 6(6), 1744-1749.

Zhou, M., Dong, S., 2011. Bioelectrochemical Interface Engineering: Toward the Fabrication of Electrochemical Biosensors, Biofuel Cells, and Self-Powered Logic Biosensors. Accounts of Chemical Research 44(11), 1232-1243.

Zhou, M., Wang, J., 2012. Biofuel Cells for Self-Powered Electrochemical Biosensing and Logic Biosensing: A Review. Electroanalysis 24(2), 197-209. 